\title{
Unmanned Marine Vehicle for Disaster Management
}

\author{
Amey Kulkarni ${ }^{1}$ \\ B-Tech. Mechanical Engineering \\ Vishwakarma Institute of Technology \\ Pune, India \\ Aditya Paranjape ${ }^{3}$ \\ B-Tech. Mechanical Engineering \\ Vishwakarma Institute of Technology \\ Pune, India
}

\author{
Neeraj Kumbhojkar ${ }^{2}$ \\ B-Tech. Mechanical Engineering \\ Vishwakarma Institute of Technology \\ Pune, India \\ Mihir Kulkarni ${ }^{4}$ \\ B-Tech. Mechanical Engineering \\ Vishwakarma Institute of Technology \\ Pune, India
}

\begin{abstract}
The idea of the project was inspired by the floods in the State of Maharashtra in year 2019. The aim of the bot is to provide essential commodities like food, clothes and first aid in areas where human help is inaccessible during flood situations. Also, the bot would be instrumental in reducing the workload on the emergency services as it can be controlled by one person only. During floods, it becomes difficult to reach out to each and every flood affected person. In such situations, a remotely controlled vehicle can be of immense help for the aid to stranded people. Unmanned Marine Vehicle (UMV) can serve the purpose by swiftly detecting stranded people and providing them the necessary help. It can be controlled remotely and detect the stranded with help of the camera mounted on it. A CFD analysis, calculations for buoyancy and turbulent forces in water were performed. The UMV was put under a short testing period in which all its essential functions were tested. This UMV will help in flood situations to supply essentials in the least time possible and also to relieve the authorities by reducing manned risks.
\end{abstract}

Keywords-Automation; disaster management; essential commodities; UMV; remote unreachable areas.

\section{I.INTRODUCTION}

Unmanned marine vehicles are used to simplify transportation of food packages, first aid, and other basic commodities to flood hit people. The basic components of this vehicle are the load-carrying unit on which the load to be carried should be placed. The load carrying-unit is attached to the motor unit. Four motors are placed in this unit which power the propellers which provides motion to the vehicle. The $12 \mathrm{~V}$ battery is connected to the motor driver then connected to the propellers. The HC -05 Bluetooth module will control the direction of motion. This helps the vehicle to move in a particular direction. With the help of ESP 32 camera module mounted on the vehicle the operator can maneuver the vehicle accordingly.

\section{Components of Unmanned Marine Vehicle are}

a. Chassis- Used for mounting of electronic components and carrying the payload. Main goal while designing it was to have a good load carrying capacity and sturdiness while keeping the relative density lesser than water for it to float. b. Motor Housing Unit- It is used for mounting of the motors in such a way that maximum power is developed to run the propellers.

c. Battery (12V)- Power the motor through the motor driver and supply the power ESP32 camera for live streaming.

d. Arduino Uno- Controlling the ESP 32 camera and the motor driver.

\section{II.DESIGN FOR UNMANNED MARINE VEHICLE.}

The design for the bot was done in SOLIDWORKS software.

\section{A. Material selection for the chassis of bot}

The material chosen for the chassis of the bot is aluminum in the form of sheets with thickness of $0.0015 \mathrm{~m}$.

\section{Advantages over other materials:}

High strength, so it can easily carry the load. Manufacturing processes are easier. The relative density of Aluminum is less as compared to other metals. During 3D printing less infill should be used to reduce relative density. Also, it's a relatively expensive method so we selected Aluminum for our load-carrying unit. Also, it can tolerate water shock waves.

Table 1: Comparison of materials for chassis of bot

\begin{tabular}{|l|l|l|l|l|}
\hline Material & $\begin{array}{l}\text { Weight } \\
\text { (grams) }\end{array}$ & $\begin{array}{l}\text { Density } \\
\left(\mathrm{grams} / \mathrm{cm}^{\wedge} 3\right)\end{array}$ & $\begin{array}{l}\text { Manufacturing } \\
\text { cost (total in } \\
\text { Rs })\end{array}$ & Strength \\
\hline Aluminum & 1300 & 0.27 & 1500 & Higher \\
\hline PLA & 3404 & 0.88 & 20000 & Lower \\
\hline
\end{tabular}

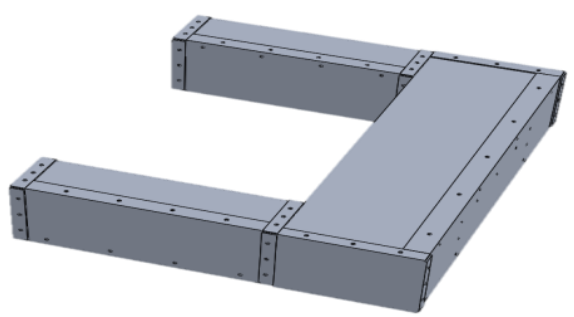

Fig 1: Load carrying unit or chassis of bot. 
B. Design of the motor housing.

a. Motor housing body

The motor housing should be able to accommodate four DC motors. The selected material for the body of motor housing was Polylactic acid (PLA) and was manufactured using three-dimensional print.

The curves and structure of housing was such that it could be difficult to manufacture using sheet metal.

\section{Advantages of PLA:}

PLA is ideal for 3D prints due to its lower printing temperature and is easier to print with and therefore better suited for parts with fine details. Moreover, PLA provided better and enough strength as compared to other material.

Table 2: Comparison of materials for body of motor housing.

\begin{tabular}{|l|l|l|}
\hline \multicolumn{1}{|c|}{ Material } & Tensile strength $(\mathrm{MPa})$ & Density $\left(\mathrm{g} / \mathrm{cm}^{3}\right)$ \\
\hline PLA & 37 & 1.3 \\
\hline ABS & 27 & $1-1.4$ \\
\hline
\end{tabular}

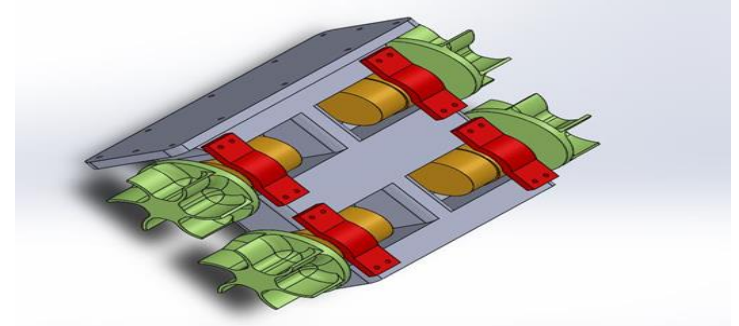

Fig 2: Motor housing unit of bot.

\section{b. Propellers}

The selected material for propellers was Polylactic acid or polylactide (PLA) manufactured using 3D Printing (with $50 \%$ infill). Four propellers were coupled to each DC motor for the required motion over water.

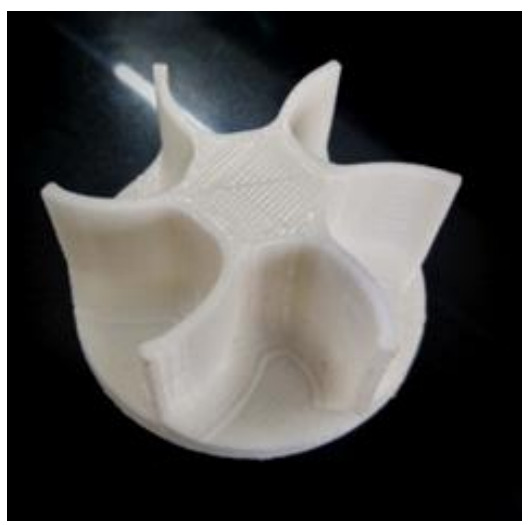

Fig 3: Propeller manufactured using 3-d print.

\section{III.METHODOLOGY}

A system of electronic components is built to supply the battery power to the motor according to the operator. For maneuverability, the power should be supplied to the motor in a specific manner. The UMV moves on the water. A device is required to find people in unreached areas which will guide the operator of UMV exactly where to move.

\section{Components required are}

\section{A. ESP32-CAM}

The ESP32-CAM is a very small camera module with the ESP32-S chip. It comes in two parts. The main board (which is an ESP32 module mounted on a larger board) and a separate camera module. Camera is of 2 Megapixels and the whole unit requires about 5 Volt power. It is provided with a micro SD card slot which is beneficial to capture and store images taken with the camera or to store files. It has an IP address which can be copied and opened in the browser for live streaming. Thus, ESP-32 camera is used for live streaming through the prescribed IP address

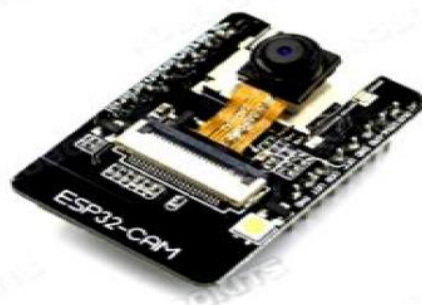

Fig 4: ESP32-Camera module

\section{B. Arduino UNO}

The Arduino Uno is a microcontroller board. It has 20 digital input/output pins (out of which 6 can be used as Pulse Width Modulation outputs and 6 can be used as analog inputs), a $16 \mathrm{MHz}$ resonator, a USB connection, a power jack, an in-circuit system programming (ICSP) header, and a reset button. It is used in UMV to receive the commands from user through Bluetooth module, process and accordingly control the power supplied to the motor through motor driver based on the code which is fed to it and also for the image processing of camera module

\section{HC-05 Bluetooth module}

HC-05 6 Pin Wireless Serial Bluetooth Module is a Bluetooth module used with microcontrollers such as Arduino UNO. It uses the UART protocol to make it easy to send and receive data wirelessly. It is used in UMV to receive commands from operators.

\section{D. $289 \mathrm{~N}$ Motor drive}

It is a high-power motor driver perfect for driving DC Motors and Stepper Motors. It uses the popular L298 motor driver IC and has a 5 Volt regulator which it can supply to an external circuit. It can control up to 4 DC motors, or 2 DC motors with directional and speed control. Motor drive is used for controlling power supplied to 4 DC motors in UMV which helps for maneuverability.

\section{E. Miscellaneous}

12 Volt battery as power source and four $300 \mathrm{rpm}$ DC motors for providing UMV required motion. 


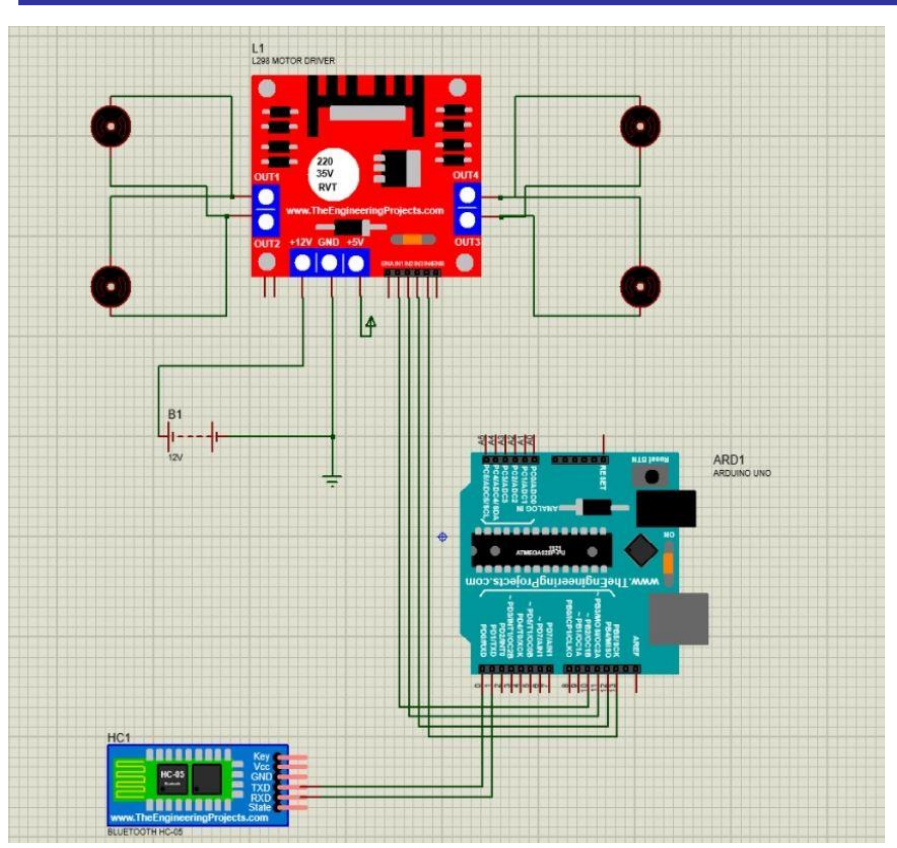

Fig 5: Motor electric circuit.

\section{IV.ANALYSIS}

By knowing quantities such as maximum velocity of the bot, dimensions equivalent to submerged bot, frontal area of bot we can get following results with help of simulation tools like ANSYS
a) Flow characteristics
b) Resistive force
c) Velocity profiles along the width of bot
d) Understanding of propeller position

Table 3: ANSYS simulation model details

\begin{tabular}{|l|l|}
\hline Model used & Fluent-K epsilon \\
\hline Input Conditions & $\begin{array}{l}\text { Velocity 3 kilometers per hour (0.866 } \\
\text { meters per seconds) }\end{array}$ \\
\hline Output Conditions & Outflow condition \\
\hline Mesh Details & $\begin{array}{l}\text { Nodes-25199 } \\
\text { Elements-127029 }\end{array}$ \\
\hline
\end{tabular}

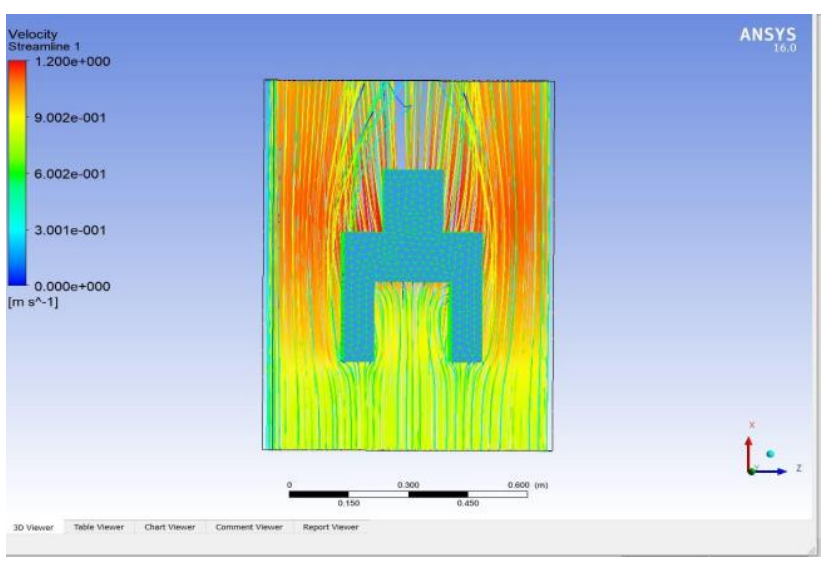

Fig 6: overall flow conditions in terms of velocity.

The above figure gives an idea of change in velocity and flow separation due to corners in the model. The flow can be improved by more streamline design which will further improve the efficiency.

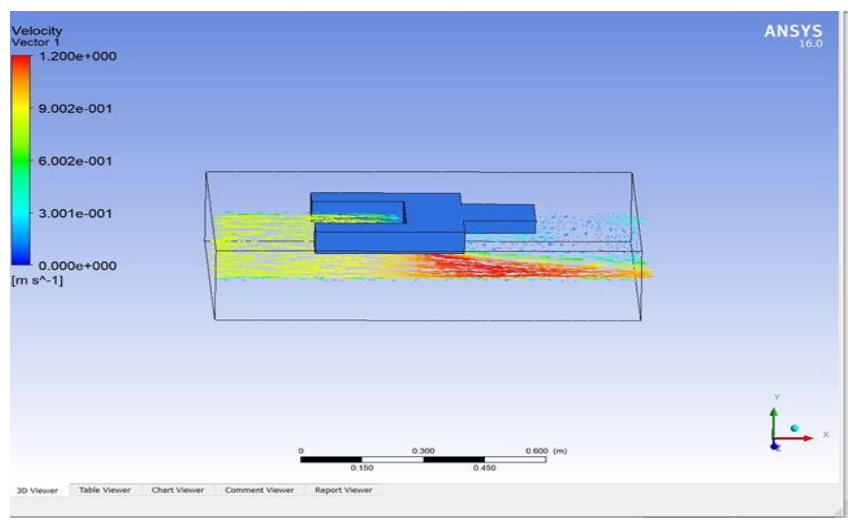

Fig 7: flow characteristics at the centre of the model.

From the above figure, the flow divergence is visible through the analysis. Also, the observation about the minimum fluid availability at the centre is considered for location of the propellers.

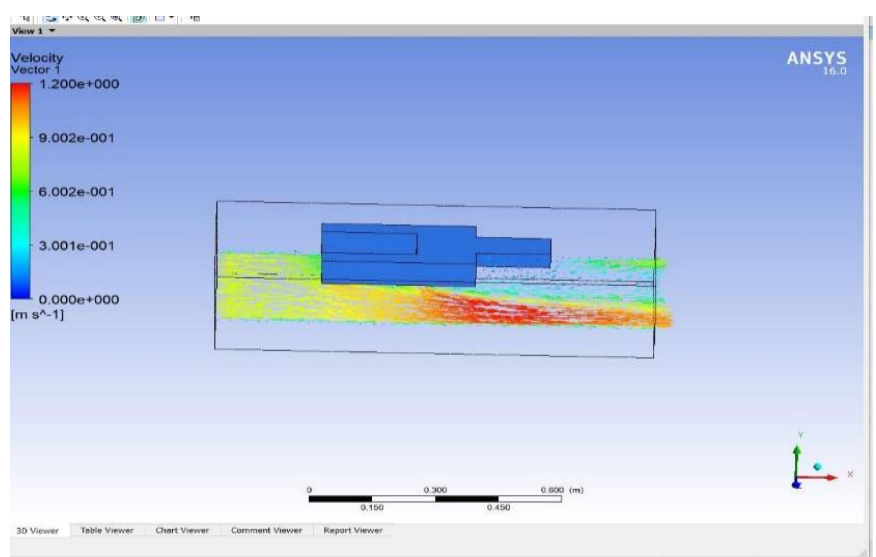

Fig 8: Flow characteristics at the inner edge of protrusion

Protrusions are the I shaped extensions part of the load carrying unit of the UMV. The analysis at the protrusion is necessary as they are the features experiencing the resistive force first while moving ahead. The inner edge characteristics help us to get a better understanding of flow.

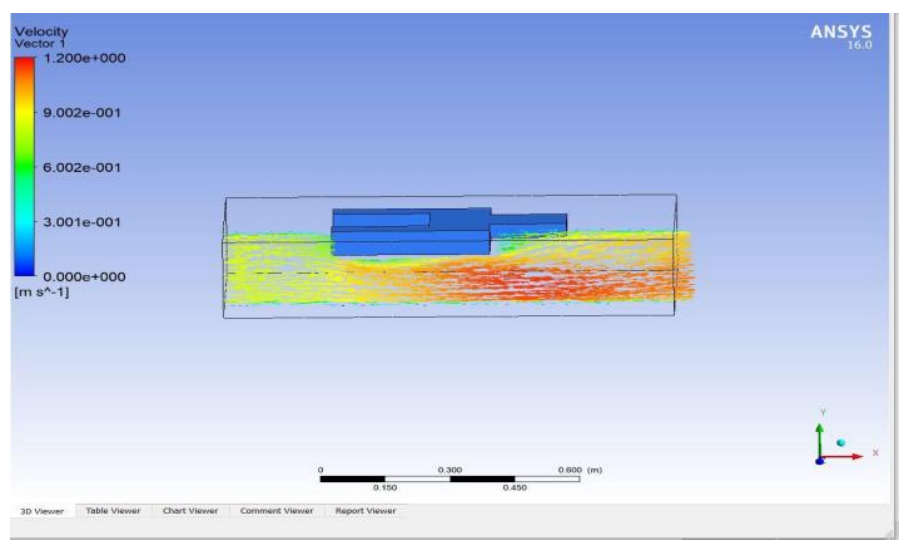

Fig 9: Flow at outer edge of protrusion

The above analysis is important with respect to the propeller system. The distance of the propellers from the centre has to be in the region where the flow of water is least affected. 
Also in order to maintain the compactness of the model the propellers should not be extremely wide owing to the better flow conditions.

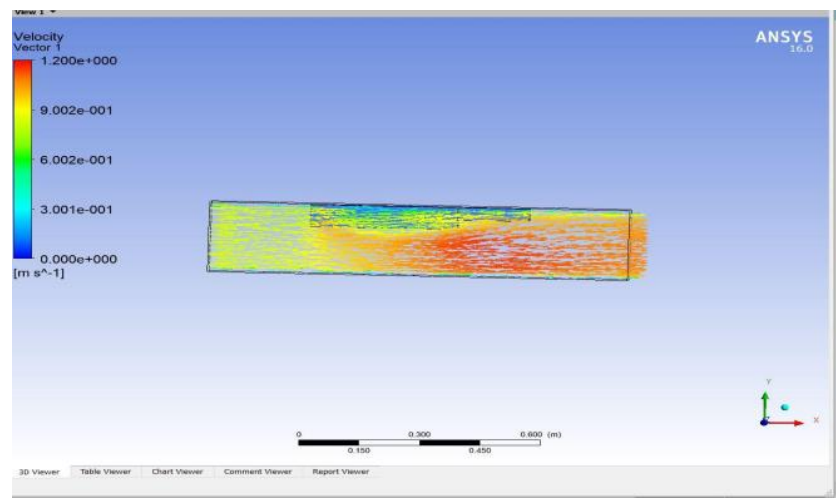

Fig 10: Flow at $25 \mathrm{~mm}$ distance away from outer edge of the protrusion

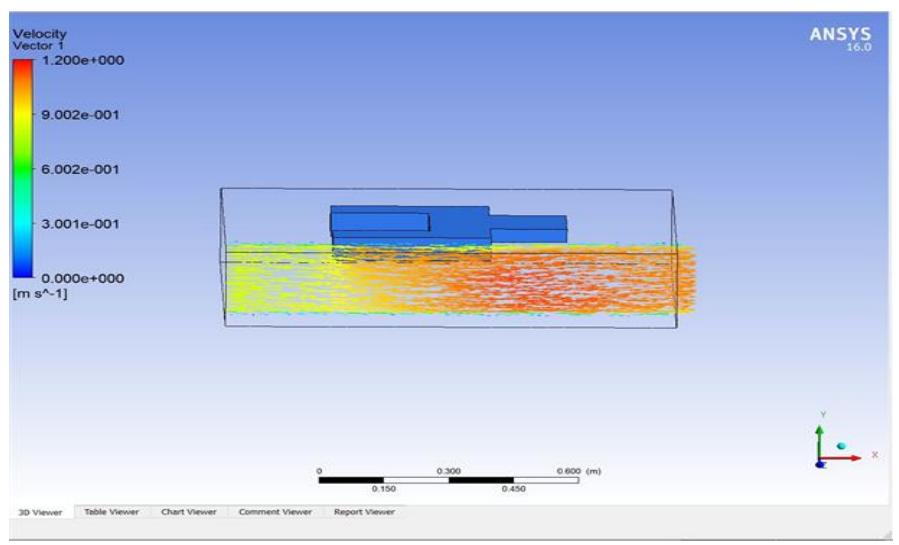

Fig 11: Flow at $55 \mathrm{~mm}$ distance away from outer edge of the protrusion

The need of analyzing above flows is to understand when the flow becomes normal and hence the position of the propellers can be placed for having maximum propulsion efficiency.

The resistive force of 45 Newton was obtained and is used for the calculations as below.

Considering the iterative calculations from above CFD, the range for resistive forces was found. This range will help us calculate the Viscous drag the model is experiencing in the water. As the drag remains nearly constant for a range of velocities of the model, this value of drag can be used to calculate the forces experienced by the model in the water at different velocities, which will help in deciding the power requirements of $\mathrm{UMV}$ (i.e., the motors which need to be used) and designing the model. A MATLAB code was generated to plot the graphs of Resistive force versus velocity at different values of drag coefficient. The top speed of the UMV is considered to be 5 kilometers per hour.

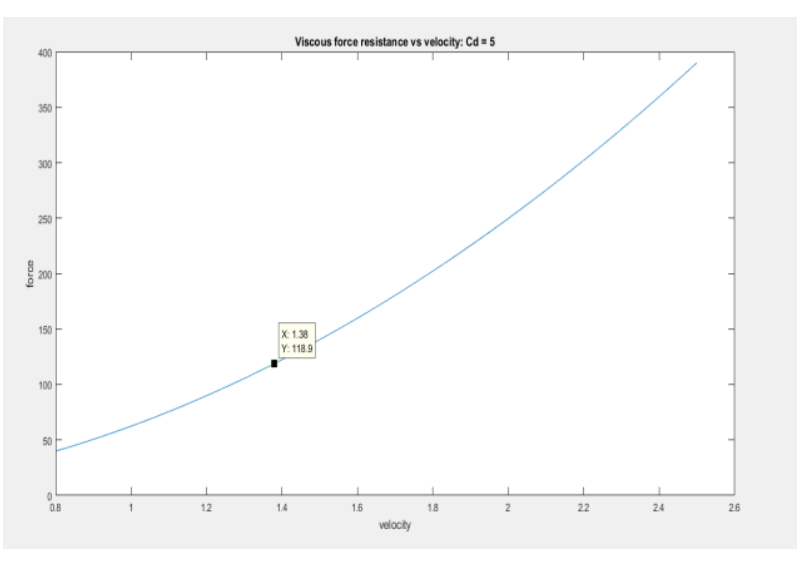

Fig 12: Viscous force resistance in Newtons against velocity in kilometers per hour considering drag coefficient as 5 .

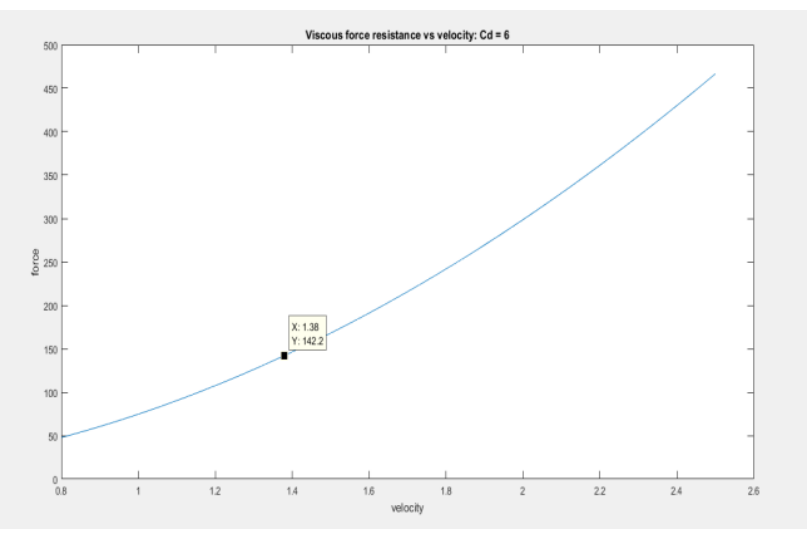

Fig 13: Viscous force resistance in Newtons against velocity in kilometers per hour considering drag coefficient as 6 .

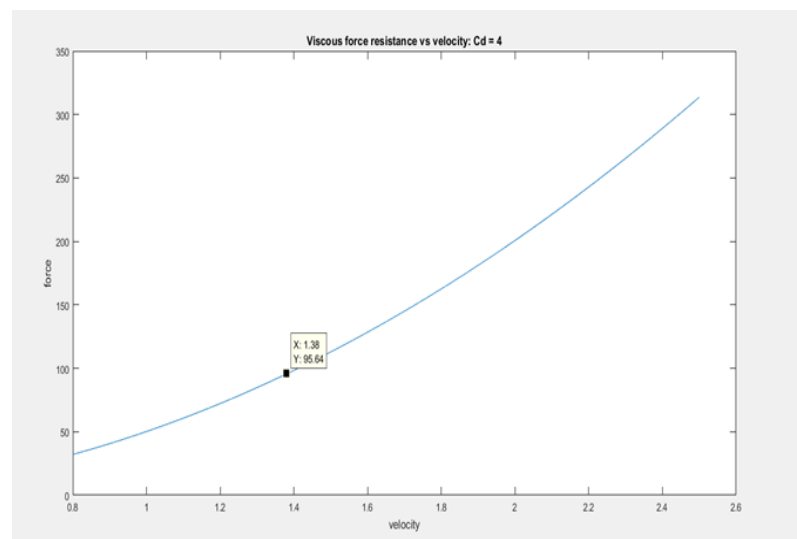

Fig 14: Viscous force resistance in Newtons against velocity in kilometers per hour considering drag coefficient as 4 .

For maximum drag coefficient 6 the maximum resistive force generated is $142.2 \mathrm{~N}$. Motor should be selected to overcome this resistive force at $5 \mathrm{~km} / \mathrm{hr}$. to propel the bot forward.

Power required to propel is given by force multiplied by velocity, i.e. 196.23 Watt $(142.2 * 13.8)$. 


\section{V.CALCULATIONS}

\section{A. Condition to float}

The basic model characteristics consist of having a relative density of the model below the density of water in order for it to float.

The model characteristics are as follows-

\begin{tabular}{|l|l|}
\hline Length*Breadth*Height & $205 * 55 * 8 \mathrm{~cm}^{3}$ \\
\hline Effective volume & $5042.4 \mathrm{~cm}^{3}$ \\
\hline Weight of UMV with load & 3240 grams \\
\hline $\begin{array}{l}\text { Relative Density with respect to } \\
\text { water }\end{array}$ & $\mathbf{0 . 6 4 2 5}$ \\
\hline
\end{tabular}

From the model characteristics and the calculations, we obtained the relative density of the model to be lesser than water which analytically signifies the floating ability of the model.

\section{B. Power requirement}

\begin{tabular}{|l|l|}
\hline Torque of motor $(\mathrm{T})$ & $1.75 \mathrm{Nm}$ \\
\hline Radius of propeller $(\mathrm{R})$ & $0.03 \mathrm{~m}$ \\
\hline Motor Rpm considered & $300 \mathrm{rpm}=5 \mathrm{rps}$ \\
\hline $\begin{array}{l}\text { Force }(\mathrm{F}) \text { generated at } 0.03 \mathrm{~m}(\mathrm{~F})= \\
(\mathrm{T} / \mathrm{R})\end{array}$ & $58.34 \mathrm{~N}$ \\
\hline Angular Velocity $=(2 * \Pi * \mathrm{~N})$ & $31.42 \mathrm{rad} / \mathrm{sec}$ \\
\hline Power $=(\mathrm{F} * \mathrm{R} * \omega)$ & $54.985 \mathrm{Watts}$ \\
\hline Total power supplied by 4 motors & $\mathbf{2 1 9 . 9 4}$ Watts \\
\hline
\end{tabular}

As earlier stated, the analytical power required to propel the bot forward is around 197 Watts. Hence according to the above results, we can see that the 4 number of motors collectively provide 220 Watts of power which is greater than the requirement.

\section{VI.ASSEMBLY}

The motor housing which is manufactured using 3-D print technique. The body of the bot was manufactured using aluminum sheet in order to have better strength. The aluminum sheets were riveted together creating a hollow entity in order to have maximum strength to weight ratio. The motor casing was too riveted to the main body. The electric motors were safely insulated from water in order to prolong their life using sealants. The controlling components were placed above the model in a way to minimize the water contact and water splashing. Two 3D printed supports were connected to the main body over which a hollow plastic box was bolted in order to have good rigidity.

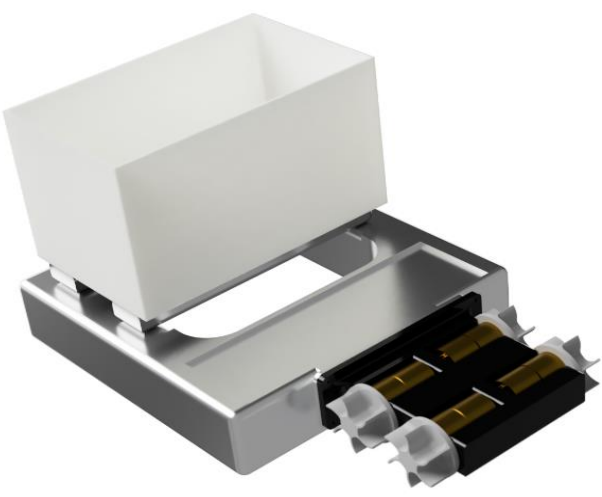

Fig 15: Final assembly of the UMV (rendered image)

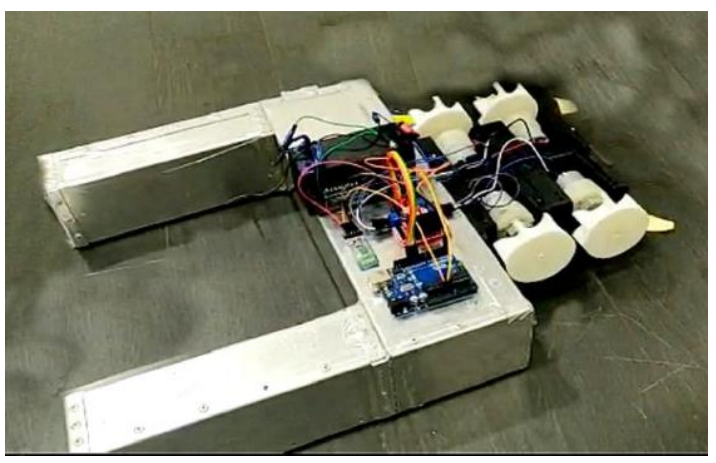

Fig 16: Image of the actual prototype build.

\section{VII.CONCLUSION}

The prototype was tested in the water tank with $1000 \mathrm{gm}$ of test weight and results were promising according to analysis and calculations. The final design is a stackable structure for easy portability with a light weight body for good buoyancy. Central U-shaped chassis with propellers and camera mountings will help to navigate and detect the stranded people and necessary supplies can be provided to them.

However, the prototype can be modified by using gyroscope and direction control devices so that it can be operated in turbulent flow. Hence, we can modify the prototype so it can sustain under extreme flood conditions.

Using waterproof roof-frame and enclosing the prototype in such a way so that it will get protected from floating debris or side impact can also be done for better results.

\section{VIII.ACKNOWLEDGEMENT}

This work is partially supported by the department of Mechanical engineering, Vishwakarma Institute of Technology, Pune, Maharashtra. We offer our sincere gratitude to Prof. Mukund Kharde who guided and supported us.

\section{IX.REFERENCES}

[1] Rameswar Bhattacharyya, "Dynamics of Marine Vehicles"

[2] Bugra Alkan,"Thrust control design for unmanned marine vehicle"

[3] https://circuitdigest.com/microcontroller-projects/how-to-useov7670-camera-module-with-arduino

[4] https://www.usna.edu/NAOE/_files/documents/Courses/EN400/02.0 7\%20Chapter\%207.pdf

[5] Ishiodu Anthony,Williams Ekwere1, Ezenwa Ogbonnayaan, Kuvie Ejabefio, "Design Procedure of 4-Bladed Propeller"

[6] R.K Bansal, "Textbook of Fluid Dynamics" 